\title{
Gender, Age and Specialization: Factors in Academic Careers of Political Scientists in Germany 1953 - 2003
}

\author{
Michèle Knodt and Peter Kotzian*
}

Technical University of Darmstadt

\begin{abstract}
Using academic careers, this paper will contribute to the empirical sociology of professions. Until recently, academic careers in Germany were highly regulated, following a predefined pattern of three steps. Contrasting with these regulations, there are numerous informal hypotheses and beliefs in the academic community about factors for success. This paper analyzes their actual impact. We find both a substantial variation and a substantial role for chance. Variation in the duration of a step is highest in the habilitation step. While there is much unexplained variation in how the Ph.D. step is executed, the two steps following are more influenced by few factors. In particular, the length of the final step - the waiting period for a professorship - is beyond the control of the individual and highly determined by the cyclical supply of vacant professorships with a fitting profile. While we cannot comment on the decision of women to leave academia, an effect of gender occurs only in the first of the three steps of a typical career, presumably due to the decision to have a child.
\end{abstract}

\section{INTRODUCTION}

Academic careers in Germany were and still are highly regulated. There are defined consecutive steps, set by law and usually abided to apart from certain, scarce exemptions. Moreover, the academic career has a clear aim shared more or less by everyone embarking on a career in this sector: reaching professorship. With a clear aim and a defined way ahead, one could get the impression that there is little role for chance. By "doing it by the book" and remaining persistent, one will finally end up with a professorship. Contrasting with this clearly oversimplified view, there are many myths and anecdotal arguments about what factually fosters or hinders an academic career, many implicitly also see a large role for chance $[1,2]$.

One must then ask, what are the relevant factors in academic careers? Obviously, the divergence between the career trajectory, as outlined by the regulations, and reality, is at least partly due to the fact that while certain steps are more or less under control of the individual, others steps depend on luck and situational factors beyond the individual's control.

The existing literature on the sociology of academic professions can give first indications about which factors are important. The focus of most research is on socio-economic factors many of which are relevant for education in general and an academic career in particular. One factor important for the decision to begin an academic career in the first place, by taking up studies, is the family background. Family background exerts its influence by at least three mechanisms: first, there are the expectations imposed by the family on the child. In academic families, the implicit expectation is that the child will maintain the "status" of the family and this

*Address correspondence to this author at the Department of Political Sciences, Residenzschloss, D-64283, Darmstadt; Tel: +49 (0) 6151 / 16 6501; Fax: +49 (0) 6151 / 16 4602; E-mail: Kotzian@pg.tu-darmstadt.de expectation will implicitly call for an academic career. Second, there is the effect on the subjective expected probability of success, which differs between a child, who is the first in a family to embark on this kind of career and a child, who comes from a family where everybody was able to master this path successfully. Last, family background also matters in terms of the financial support available, which is usually higher in academic families. The financial support available matters from early on, when the pupil is in need of additional or more intense educational efforts, such as private lessons. But financial support matters also later on. Embarking on an academic career implies costs, due to the renouncement of income for quite a long time, but also due to costs associated with studying. In the German case, these costs were until recently not tuition fees imposed by the universities but the usual costs of living, like rent etc. Empirical work, on the level of higher education in general but also throughout academic careers, has corroborated these socio-economic effects [3]. In particular, work done by Abedi and Benkin or Gillingham et al. indicates that these factors also affect the time required to obtain a doctorate, when the student is usually less dependent on the family's support $[4,5]$.

Another systematic factor discussed intensely and controversially is gender. Empirically, women are underrepresented in academia $[6,7]$, leave academia more often, $[8$, 9], and achieve certain steps slower [10]. Several reasons for these differences are discussed, for instance the argument that women attend less prestigious universities [9], or are less productive than men [11]. Both arguments shift the problem one step back, to the question of why women chose less prestigious universities and produce less output. So far, none of the explanations have proven to be conclusive. As a consequence, the debate focuses on the reasons and mechanisms, in particular the role of "pure biology", and also on the impact of policies to promote women in science [12]. 
The unsystematic factors in careers are luck and chance. Luck can express itself in the form of help from a third party, like a mentor who is actually engaged in helpful supervision, for "pushing" the candidate on in supportive way [13]. Random factors like the place of the family's residence and the closeness to universities may also have impact. While the prestige of a university affects the chances later on - for an academic career as well as in the non-academic job market [14], it might not be the strongest determinant in choosing a particular university in the first place. Luck can also take the form of being embedded in informal networks, e.g. getting a position to obtain a Ph.D. in a department, which is well connected within the discipline $[15,16]$.

As for the features of the individual, talent and effort interact and can affect the career in many positive ways. But many of them are also double-edged in their effects. As for the role of effort, the individual can speed up the process by working harder. The individual can also try to obtain a stipend which allows to concentrate on the academic work required to obtain a certain qualification (writing the Ph.D. or habilitation thesis). This allows the applicant to obtain a certain degree faster than others. However, getting a stipend or a research grant is not only a question of effort, skill or talent, but also a question of luck. There are subject areas, which are en vogue, and others which are out of favor [17].

The individual may have bad luck in the sense that the financing of a step of the career requires working on a project unrelated to the individual's own research or the fulfillment of teaching obligations. By limiting the time available to work on one's own research, both situations will slow the individual down. Personal "bad luck" can also mean to be born at the wrong time, the implications of which are discussed in detail by authors like Easterly [18]. For instance, all students born in a certain period will enter the university at about the same time. The size of their cohort will be a shared feature for all cohort members and will influence their chances throughout their life. If the cohort is large, it will suffer from lower quality of education, in particular less intense supervision, because the number of professors will not be increased to cope with the higher number of students and the time "invested" by a professor in each student will be lower. On obtaining the degree, the larger cohort will enter the job market also roughly at the same time and the job market may not be able to cope with the large number of entrants. This is true especially for the academic job market which is quite stable in the short run. Furthermore, the pool of available funding for grants, is also stable in the short run, and will be depleted more quickly if more potential candidates are applying. The chances of getting funding, e.g. a stipend or a research grant, will thus be lower for some cohorts [18].

The observation of differing opinions about the role of factors and events relevant for careers arises from the fact that more or less all these features have, at least potentially, double-edged impacts. Most people in academia know cases in which a certain event was of advantage, but also cases in the very same event was disadvantageous. For instance, getting a grant to work only on a specific project - ideally one's own - saves time but may also isolate the individual from the academic community. The latter is, however, less likely if the individual is strongly involved in the day-to-day business of a university. So, while the holder of a grant may finish a certain step quicker than others, she may be rather unknown in the academic community, which makes it more difficult to get a job, the affiliation, or the funding required to accomplish the next step.

Summing up the myths, findings and arguments, one can say that according to the overall impression held in the academic community, chance plays a strong role in the career path, which does not automatically favor the most talented persons. While reporting these hypotheses and beliefs held in the community, this paper is not about theorizing. It is about testing some of the conjectures commonly held among German political scientists. Contrary to existing literature, our focus is on how properties of how the steps of an individual's career are passed through affect the career.

The structure of the paper is as follows. In the following section we will describe the regulatory setting for academic careers in Germany, the steps, the formal and informal "rules of the game". Despite some recent convergence in the national markets for academics in the EU, with the acceptance of qualifications and increased movements [19], the obtained results are still specific to Germany. Next, we describe the dataset and variables. The dataset has a strong self-selection bias as only persons who made certain decisions are still member in the political scientists' professional association, DVPW, the population from which the sample is obtained. This limits the possibilities of explaining decisions because those who decide to leave academia also leave the DVPW. Lacking data on nonDVPW members, we cannot make any inferences about their reasons for leaving. Given this limitation, the point of interest is instead what can be revealed about the factors influencing the speed with which steps along the way are accomplished.

The empirical analysis is structured by the steps - Ph.D., habilitation, professorship - for each of which we will look at the factors influencing the duration. This paper differs from studies like the one by Long et al. [10], in that it does not follow a group of academics for a given period of time, but rather looks at a sample consisting of different cohorts where the higher echelons of a career trajectory are overrepresented because persons who dropped out at earlier steps also left the study's sample. The focus is on the way a career is pursued, how a step is financed, whether the person changed location, whether the person specialized and in particular, when the person entered the market for professorships.

\section{ACADEMIC CAREERS IN POLITICAL SCIENCE IN GERMANY 1953 TO 2003}

\section{Patterns in Academic Careers}

The pattern of an academic career in Germany during the period studied here, is set by binding regulations. The regulatory imposed pattern is identical for all academic disciplines. Despite some variation among the regions, the Bundesländer, which are in charge of all regulation concerning education and academics, the pattern is also basically identical all over Germany. A recent attempt of a 
major reform in 2002 was revoked again by the federal constitutional court. Only certain aspects of the reform package came recently into force. For the purpose of this study, the regulatory framework remained constant for the period of the study.

Given the extensive regulation, it is fairly easy to describe what the prototypical academic career looks like. After obtaining an university degree, one must obtain a Ph.D. and then habilitation, i.e. the degree of a "Dr.habil." which formally enables the holder to professorship. The steps after the university degree are no longer under the control of the applicant, but depend substantially on outside factors. Both for getting a Ph.D. and habilitation, the individual must obtain affiliation to a professor acting as a supervisor.

Obtaining professorship is a matching process of candidates applying for open positions, whose profile is defined by the university's profile and relatively stable. For some sub-disciplines there are many professorships, for others only few. From the perspective of the person looking for a professorship, this matching usually entails a waiting period which is financed by filling a position somewhere at a university, through stand-in professorships, or via other sources such as research grants or teaching assignments.

The final step in an academic career, the professorship, is a call from a university, and the first professorship a person obtains, is denoted as "first call", "Erstberufung". Once a professorship becomes vacant, there is a formal and usually public tendering of the position, to which everybody fulfilling certain criteria - every Dr.habil., but also candidates in their last phase of habilitation, but also professors from other universities - may respond. Some applicants are informally encouraged to apply by members of the faculty. The faculty invites only a selection of the applicants for a meeting to give a presentation to a commission consisting of members of the faculty and other, external members. Apart from the presentation, further criteria considered are publications, teaching experience, and the success in acquiring grants. The decision process varies in detail. Typically, the commission makes the decision, usually by consensus, on a ranking and compiles a short list, usually of three candidates. Based on this list, a call is issued to the person in the top position. Only in the case that the first ranked applicant refuses the offer, the second or third ranked applicant is called. If all three refuse, the process starts anew.

Given that the number of professorships is always limited and, moreover, quite stable in the short run, the last step is beyond the control of the individual and supply driven. Not least because of the aftermath of the Second World War, there is a cyclical pattern rather than a continuous replacement. An example of "good luck" is when the individual has accomplished all necessary steps at a time when many professors retire, leaving positions vacant or new positions are created, like in the late 1960s. "Bad luck" is when the individual finishes all necessary steps just after the majority of chairs have been filled recently. Since professors cannot be laid off for the reason that there is a better candidate for the position, a position only becomes vacant if the professor leaves voluntarily, either to assume a better position elsewhere or to retire. It is thus clear that talent and effort are only of limited impact in the last step of an academic career. This last step, the process of getting a professorship, is best seen as driven by the supply of positions, calling for an inclusion of supply side factors in the empirical analysis. Fig. (1) gives an simplified overview on the stages and decisions along the way to professorship.

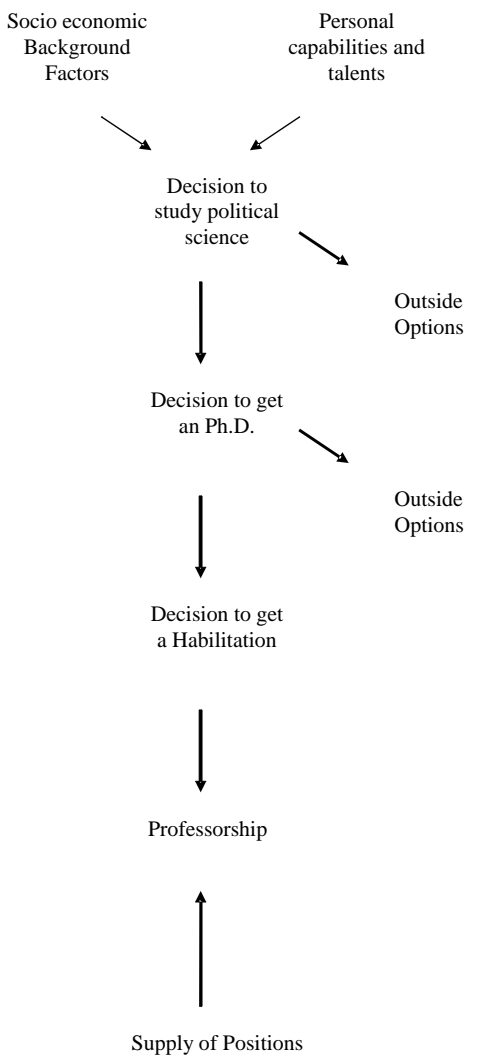

Fig. (1). Stages and decisions in academic careers.

To summarize, while each step of an academic career is structured by regulations, the reality becomes less structured as the career progresses. It is clear what one must do to get a university degree and a $\mathrm{Ph} . \mathrm{D}$. It is also clear that personal effort and talent play - ceteris paribus - an important role in these first steps. But experience seems to indicate that after these steps are concluded, the role of chance increases dramatically and the actual events are less under the control of the individual. In the empirical sections, we will refer to the variation at each step as an indicator for the role of chance. The variation and the degree to which the explanatory factors used explain this variation, will serve as an indicator for the degree to which each step is standardized.

\section{Conjectures and Hypotheses about Successful Academic Careers}

There are a many possible factors which are conducive or obstructive to an academic career in political science. Our focus will be on features, describing, how persons conducted their career. Because the issue is so often debated in both academic and political circles, we will look especially at gender-specific differences in the career path. It is here that 
things have changed most, at least formally, though the factual effect is still unclear. For instance, universities now actively encourage female applicants and universities will often announce that in the situation of equal appropriateness in terms of academic record, however defined, the university will choose the female applicant. The question is, therefore, whether this effort is effective for increasing the number of female academics. There are expected differences in timing between women and men, mostly due to the fact that women may go through a pregnancy which is time consuming. There is the question, whether women drop out of academic careers more often. A further question is when the observable gender differences start to appear - is it at the beginning, when students decide for or against an academic career, decide to study political science rather than something else? Or is it later on, in the beginning of the actual career? Do females embark equally often on an academic career, but quit more often, as found for instance by Preston [8]?

Other hypotheses and presumptions concern certain properties and activities of the individual during her or his career. We are forced to focus on the ones for which we have testable data. Given that the community is rather small, a natural question is whether an individual's networking is important for a particular step. Is a period abroad an advantage or a waste of time? Do applicants who have "excelled" by getting a stipend complete a step faster than others? Does the length of each step affect the length of the following step? Is the length of a step primarily dependent on financing? Does subject area matter, i.e. the focus of research? Is it better to specialize or to be a "generalist"? For all of these factors there is plenty of anecdotal evidence of impact but no actual empirical information. Moreover, the evidence and the arguments for a certain effect are usually ambiguous and double-edged. Having a position which involves teaching may slow the applicant down; on the other hand, having teaching experience may be a valuable asset when applying for a position, reducing the time needed to find a position.

Unfortunately, no information is available about the quantity or quality of academic output, i.e. papers in peer reviewed journals and monographs. Long et al. for instance, found that the number of publications is much more important than their quality; [20]. But anecdote has it that in some sub-disciplines of political science, an article published in the "right" journal may well earn a professorship.

There is also no information about the effect of having obtained a degree at a prestigious university or at a prestigious chair, which might also be influential [14]. The implicit argument is that some universities are the soft option and degrees obtained there are somehow less valuable, and vice versa. While we have information about at which university the respondent obtained his or her degree, there is no data about the reputation of the universities at the time that the degree was obtained. There are some rankings of departments, done by the media, but they cover only recent years.

Another factor in getting an academic position is age. While some argue that the ideal professor is supposed to be still quite young, while of course having at the same time sufficient experience in teaching and in acquiring research funds, plus an extensive publication record, others argue in line with the seniority-principle that a certain age is necessary; see Caplow and McGee for the original argument; [21].

With regard to obtaining professorship - the last step of an academic career - the question is also whether vacancy cycles are important. Or rather, how important they are. There are discernible waves in the rates how professional positions are filled, observable also in our data; see Table 1c below. There are times during which professorships are created respectively, where many professors retire, creating many vacancies. There are also times when all positions have been recently staffed, no vacancies are available, and moreover, none will be available for years to come.

\section{PROPERTIES OF THE DATASET AND THE POSSIBILITIES OF INFERENCES}

The dataset used in present study is a survey conducted in summer 2003 among members of the German Association of Political Science (DVPW). About 30 percent of the DVPW members participated in the survey by completing the questionnaire which was sent out to all members. The gross sample size is 426; respondents received their university degree in the period from 1953 to 2003. The sample is representative of the overall composition of the DVPW in terms of demographics and academic features.

The respondents were asked to give the year in which they reached a certain academic degree (graduation, Ph.D., habilitation, professorship) as well as certain demographic information. Further information is available on how they conducted their careers up to the time of the survey: the subject area in which they work, the way they have financed certain steps, their mobility both within Germany and abroad, and their involvement and activity in the DVPW.

\section{Possibilities of Statements and Inferences}

The obvious problem of the survey is that the DVPW, as a population, is subject to a self-selection-bias/survivorshipbias in two regards:

First, there is the usual self-selection bias entailed by sending out a questionnaire which may or may not be returned. Nothing can be inferred about the distinctive properties of those who did not participate as opposed to those who did. It might be that the more active members are also more willing to participate in this survey, driving up the average of activity indicators. There is no obvious or plausible reason why the variables and the averages we are looking at should be related to the willingness to participate. Thus, we accept this limitation. But as said above, the sample is representative of the DVPW in regard to basic demographics and academic degrees.

Second, there is another source of self-selection bias in that the population from which the sample is taken is already a self-selected one, with the selection process being based on a dependent variable, a problem discussed in detail by King, Keohane and Verba [22]. Only individuals with either an academic job in political science - or with the ambition to get one - are members of the DVPW. The members of the DVPW made certain decisions and achieved certain steps. Persons who decided otherwise, or did not achieve this step, 
dropped out of academia, renounced membership in the DVPW and are no longer in the population from which the sample is drawn.

The choices and steps leading to the biased composition of the DVPW as a population are the following: the first decision is to choose political science as the discipline of study, followed by the decision to finish studies in this discipline. In particular in social sciences, drop-out rates are reported to be rather high compared to other disciplines. After having obtained the university degree, many decide to leave academia for a job in the "outside world". Those who choose to do so are not in the DVPW. Therefore, we can comment neither on them, nor on the differences between them and those who decided to remain on an academic track. There may be relevant variables, but we cannot compare the two groups, because there is no information on those who left. The next step is the decision to go for a Ph.D. in political science, followed by the decision to actually complete it. Again, no information can be offered regarding those who decide to drop-out during this step. One can suppose that certain factors affect the appeal of outside options, but this argument is based on plausibility only. After having obtained a Ph.D. the point is again reached when leaving academia is a reasonable and serious option chosen by many. Once again, we have no information on those who leave academia and the DVPW. The next step after the Ph.D. is achieving habilitation. Writing a habilitation thesis, again, involves several years of research which have to be financed. As before, persons leave during this phase - and we identify neither them nor their motives and cannot compare them with the ones who stay on.

This is also true for the last step. One could argue that the ones who obtain habilitation are, more or less, forced to stay in academia permanently. The reason underlying this argument is that the individual's investment in an academic career at this point in time has been very high already and is virtually of no use (compared to a Ph.D.) outside academia [2]. Moreover, at this stage candidates are often perceived to be too old, and too set in the ways of academia, as to be of interest for employers in the private industry. As a matter of fact, according to our sample, virtually all individuals with a habilitation also became professors. The only difference is the time they waited for professorship. This could imply that the argument is indeed true and the Dr.habil. do not leave academia. However, we have again no hard data on how many people actually leave at this step, because if they do, they also will leave the population from which the sample is drawn.

Regarding the implications of such a sample for the possibilities of analysis and inference in particular, the logical limits are obvious. The population is defined by political scientists fulfilling certain criteria and all statements are conditional on these features. The central feature is that they decided for a certain career, and stuck to it. Because we lack information on those who decided otherwise and left academia and the DVPW respectively, we can say nothing about the motives for their choices, and consequentially cannot analyze the decision. Because we also lack reliable data on the initial composition of each "generation", we cannot say, whether the features shared by those who stayed on are decisive for staying on.
Given this dilemma, what can we say about the role of factors along the way?

One possible option would be to weigh the cases based on outside information on the frequency of a certain combination of features in the overall population. A tempting strategy would be to make an inference on features favoring a certain decision from looking at the features of those who made the decision. For instance, if women are more likely to drop out at a certain step along the way, the share of men will increase from one step to another; see the study by Anne Preston for a discussion of exit decisions; [23]. Since professors are more often male than female, the inference would be that gender is relevant and men stay on and become professors more frequently. However, the proportion of women to men might have been skewed from the beginning, i.e. when those who are now professor chose political science as a discipline to study, an alternative interpretation which is just as likely; cf. the work by Mary Frank Fox for gender specific choices of academic disciplines; [9]. Similar drop-out rates for both sexes then result in the observable skewed distributions in higher echelons. We have no information about the composition of the cohorts of students who decided to study political science several decades ago, thus we cannot answer this question.

Since a certain echelon corresponds to a certain cohort, we cannot distinguish different drop-out rates from different initial distributions if we do not have outside information about the latter. As this information is available only for the most recent cohorts, this strategy cannot be used. Given these caveats, we are restricted to the analysis of "success" in the sense of the time required by those who achieved a certain step.

\section{Dependent Variables}

Regarding the dependent variables, the respondents were asked to give information on whether and in which year they obtained their university degree, when they obtained their Ph.D., habilitation, and/or professorship. The dependent variables are the length of each step in years: dpromo is the duration of the Ph.D. step, dhabil is the duration of the habilitation step and waiting is the waiting period between finishing the habilitation and getting the "first call", i.e. the first professorship. The analysis of the time required to conclude a certain step refers only to those cases in which this step was actually achieved.

\section{Explanatory Variables}

\section{Features of the Individual}

\section{Gender}

There is much debate about the conditions of women in German academia. We will look at whether there are significant differences in the lengths of the steps and at what stage.

\section{Funding}

Most funding of a career step takes the form of having a paid position, either in a department or in a project financed by a "third party", like the German Research Foundation. Either way, this kind of financing implies that the individual 
is occupied with other tasks, such as teaching or working on a project, which may or may not be related to the individual's own research. While it is usual for the individual to be strongly involved in writing the grant proposal, the formal applicant is a professor, who is later the employer of the individual. Until very recently, it was not possible to submit a research proposal to finance one's own position. There is also the possibility of applying for a stipend which is explicitly aimed at allowing the recipient to research unhindered by other tasks. In particular, we look at the impact of a stipend both as a mark of excellence and as a chance to focus on one's own research.

\section{$\underline{\text { Mobility }}$}

Captures whether the individual changed universities during a certain step or during the career. The mobility variables cover a change of locations between graduation and promotion, and a change between promotion and habilitation. During these two steps, the candidate is free to change or to remain at their university. Only after habilitation does the Dr.habil. have to leave his/her home university to obtain a professorship elsewhere.

\section{$\underline{\text { Abroad }}$}

Captures whether the individual went abroad for at least three months. Some argue that the experience of having been abroad, either for research or teaching, is a major advantage. Others claim that it is basically a waste of time, disconnecting the individual from the community back home. For the first two steps, the variable refers to whether the individual was abroad during these periods; for the waiting period, the variable refers to whether the individual was abroad at least once.

\section{MultiFin}

Changes in funding are a potential indicator that things did not go according to plan. For instance, because of differences between the candidate and the advisor, who is usually the formal applicant for the funding and organizer of the individual's employment - or because the step took longer than expected. In any case, getting new funding means that time is required to look for new sources, i.e. one would expect that this prolongs a step. A change in funding is also a "time at risk" during which a candidate might reconsider the plans and exit the academic career altogether. At the very least, it presents an interruption in the sense that a new grant must be acquired - which takes time for writing the proposal and waiting for a result - or a new job has to be found. The variable indicates whether there is an advantage in having a secure financing for a given step.

\section{$\underline{\text { Activity }}$}

Networking in the DVPW, the major professional association, might be an important factor in getting a job or the "support" necessary to make the next step. There are yearly congresses, and people can present themselves in section meetings and workshops. A problem of the indicator is that the question focuses on the current activity, with no information about past activity. However, it is possible to see activity in the DVPW as a stable trait of the respondent. The variable activity counts the number of memberships in
DVPW sub-organizations. There are three types of these: sections, working panels and ad-hoc-groups.

\section{$\underline{\text { Age }}$}

Age is included by using the age of the candidate when he/she starts a certain step. For the Ph.D. step, age_grad is the age on receiving the university degree, for the habilitation phase, age_phd is the age of the respondent on getting the Ph.D. For professorship; it is for technical reasons also this age because some professors obtained professorship without completing a formal habilitation. The usual hypothesis is that being rather young is an advantage when applying for a professorship. However, the other advantages - like research and an extensive record of publications - are more correlated with age.

\section{Period and Cohort Effects}

Given that the time frame we are covering is approximately 50 years, there is reason to believe that time specific context factors play a role. An initial factor is the cohort of students. A property of the candidates is the period from which they originate, i.e. during which the student obtained the degree or a candidate achieved a certain step. There are features of the cohort which are characteristic for a particular cohort. For instance, the size of the cohort and also the distribution of the candidates among sub-disciplines of political science [18]. The cohorts of origin we use are defined by the year in which an individual received their university degree. They are grouped into the pre1975, the 1976 to 1985,1986 to 1995 and the post1996 cohort. The reference used for the analysis is the pre 1975 cohort.

Obtaining a professorship is conditional upon the availability of vacant positions. Thinking about the issue in an age-cohort-period-framework, the feature of how many positions are free in a certain period is conceptually independent from the features of a certain cohort of candidates, for example the cohort's size. For instance, during a certain period, many new positions may be created for whatever reason. In such a period, basically every candidate, whether on the market for a long or a short time, with the necessary qualification is likely to get a position. On the other hand, a cohort of candidates, all of whom completed all steps at roughly the same time, may enter the market for professorships in a period where there are only few positions available. The long waiting time for this cohort is then a result of a feature of the period. As with all agecohort-period effects, the features are not empirically independent and it is impossible to differentiate among their effects. We will use two alternative versions of the periodical effects which capture properties of the market for professorships.

First, looking at the distribution of "Erstberufungen", i.e. persons receiving their "First Call" to a professorship, there is a distinct cyclical pattern; see Table 1c. We will look at the effect of periods in which many or few positions were factually occupied. The dummy variables of "Professorship Cohorts" we are using to reflect this cyclical pattern are pre1979, which is the reference category, and the decades of $1980-89 ; 1990-99$ and post2000. The variable has the value of 1 , if the First Call was received in this period, 0 otherwise. 
Secondly, we will look at the point in time when the candidate enters the market and starts to look for a professorship. The time of market entry refers to the year/period the individual concluded the habilitation. The dummy variables of "Entry" we are using are again the pre1979 period, which is the reference category, and the decades of 1980-89; 1990-99 and post2000.

\section{Specialization and Themes of Interest}

There are at least two reasons why specialization is important. The first reason is that some subject areas are, for whatever reason, constantly much more en vogue than others during certain periods, e.g. Political Theory in the early 1970s. Others, like methods and statistics, are constantly out of favor. The second reason is that the number of positions and chairs available for an individual who specialized in a certain theme differs. For instance, there are many chairs and positions covering the German political system, since this is part of any syllabus at any university offering a degree in political science. The impact of specializing on a certain theme is again ambiguous. On the one hand, students may focus on a topic for which the academic market is large because there are many positions available. On the other hand, the opposite it possible too, causing students to specialize on an area for which the market is smaller, both in terms of available positions but also in terms of competition for the positions. A further factor are the outside options a certain specialization offers. A student with a focus on statistics can leave the academia and go into another discipline where statistics is required, or go into market research or opinion polling.

The main themes were included by dummy variables for the focus of the individual's interests: Political Theory and Political Philosophy; Methodology including statistics; German Politics - the study of Germany's political system including public administration, policy research, all of them with a clear focus on Germany; Comparative Research; and International Relations.

\section{Multi_Task}

Is a dummy variable, capturing whether the individual is active in at least two themes of interest and expertise. On the one hand, having more than one focus and being a somewhat of a "generalist" is an advantage since it increases the number of potential positions one can apply for. On the other hand, lack of specialization entails a certain superficiality which may be a disadvantage in that if one has applied for a job, others candidates may offer a better fitting $\mathrm{CV}$ and publication record.

\section{RESULTS}

In Germany academic careers are highly regulated and there are few exemptions from the common pattern. While, as argued above, we cannot comment on the chances for a respondent making a certain step, we can analyze the duration of each step. We will look at the effects of the features and properties listed above on the length of each step.

\section{Some Descriptive Statements}

Table 1 below offers some descriptive statements about the duration of certain steps and the development over time.
Regarding gender-specific differences, the finding in section a) of Table 1, is that women appear less frequently in the higher echelons of academic careers. Insofar, the findings confirm those found by the studies mentioned above. However, we cannot comment about the decision process leading to this outcome and we have no information about the original distribution of men and women for the point in time, when the members of the cohort which is now holding professorships, began their careers. It may be that women left academia more frequently then men. It might also be that women were underrepresented in political science from the beginning and drop-out rates are equal. Lacking data on the original distribution of the students in the cohorts, we cannot differentiate between explanations.

For the overall sample, both the average duration and the variation in duration is highest for the habilitation step. But looking at the sub-samples of cohorts, given in section b) of Table 1, one can see that the high average of the habilitation duration concerns only the pre1976 cohort. This fact is due to the singular historical event of an extreme surge of newly created vacancies, following the creation of positions in the wake of the 1968 events. Many of these persons obtained a professorship when they still had only a Ph.D. but no habilitation.

An interesting finding visible from section $\mathbf{b}$ of Table 1, is that there is an overall tendency to speed-up the academic career; the average duration of a step is decreasing in the younger cohorts of graduates. Furthermore, duration tends to vary less in the younger cohorts than in the earlier ones. Section $\mathbf{c}$ of Table $\mathbf{1}$ shows that the supply of positions is highly cyclical. First calls in the periods after 1980 require vacancies, usually due to retirement, because no new positions were created. For those entering the market in the 1980 s, the number of positions was only half the size than for the preceding and the following decade.

Fig. (2), illustrating the data given in Table 1a, shows the composition of those DVPW members who have at least concluded a certain step. It allows an insight into the dropout rates and the composition of each groups. The drop-out rate is high, resulting in an overall sample in which higher echelons predominate. The most drop-outs occur after obtaining the Ph.D. which is a stage which offers itself for leaving. Common knowledge in the field has it, that, if one plans to leave, one should already start looking for a job outside academia in the last stages of writing the Ph.D. thesis and not engage into another project after concluding the Ph.D. Having achieved the Ph.D. is seen as the best, and to some degree also as the last, moment to leave.

Among the youngest members of the DVPW, the gender composition is roughly equal; cf. Table 1a, but the ratio of men to women changes distinctly in the higher echelons. However, as we elaborated earlier on, one cannot say, whether this is due to higher drop-out rates for women in earlier years or due to the fact, that fewer women chose political science in the first place.

\section{Length of Career Steps for Political Scientists}

For those who actually accomplished a particular step, we examine the factors influencing the duration of the certain step. We tested especially for effects of those factors 
Table 1. Steps of Academic Careers in Germany: Descriptive Measures

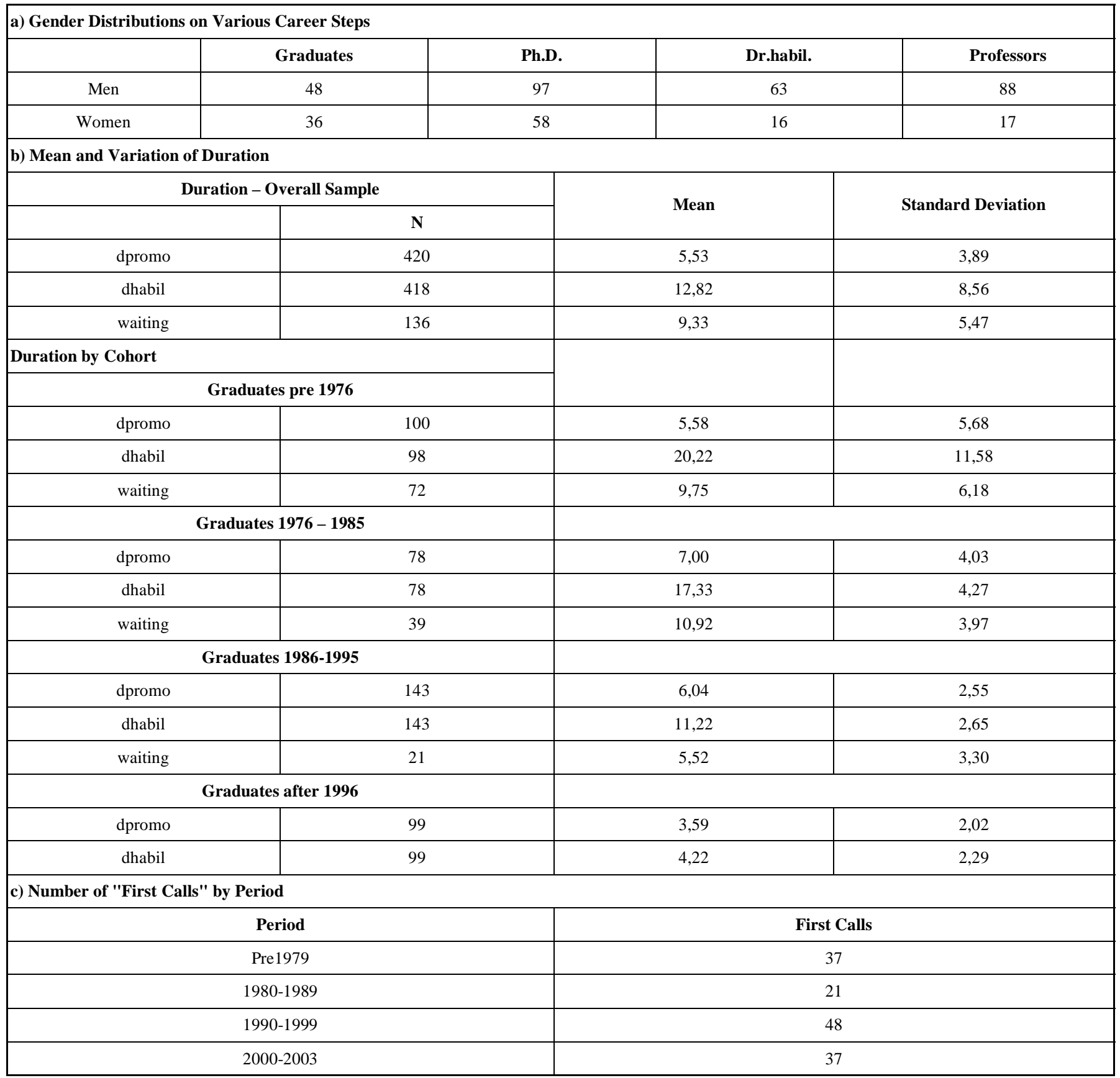

which according to "common knowledge" are influencing the career. In terms of Fig. (1), we will look at features of the candidate's career so far - in particular the way a candidate finances a certain step of the career - and their effect on the time a candidate needs to achieve a certain step. As for the socioeconomic variables, we will focus on potential differences between women and men and also, on which steps these differences are occurring.

We can interpret the model fit, the $\mathrm{R}^{2}$, as an indicator of the role of chance and luck in the various steps, but also as a measure of the degree to which a certain step is "standardized". For the interpretation it is important to keep in mind that we only analyze the subsamples of those who actually achieved the step. Since we include the candidate's age at the beginning of a step, the constant obtained by the regression can not be interpreted as an average or baseline. Table 2 below shows the results.

\section{The Ph.D. Step}

Looking at the step during which one gets a Ph.D., we regressed the length of the step - measured in years - on features of the candidate. Overall there are few significant effects. The $\mathrm{R}^{2}$ of .21 and the adjusted $\mathrm{R}^{2}$ of .16 indicate a low explanatory power of the features we have at hand. 


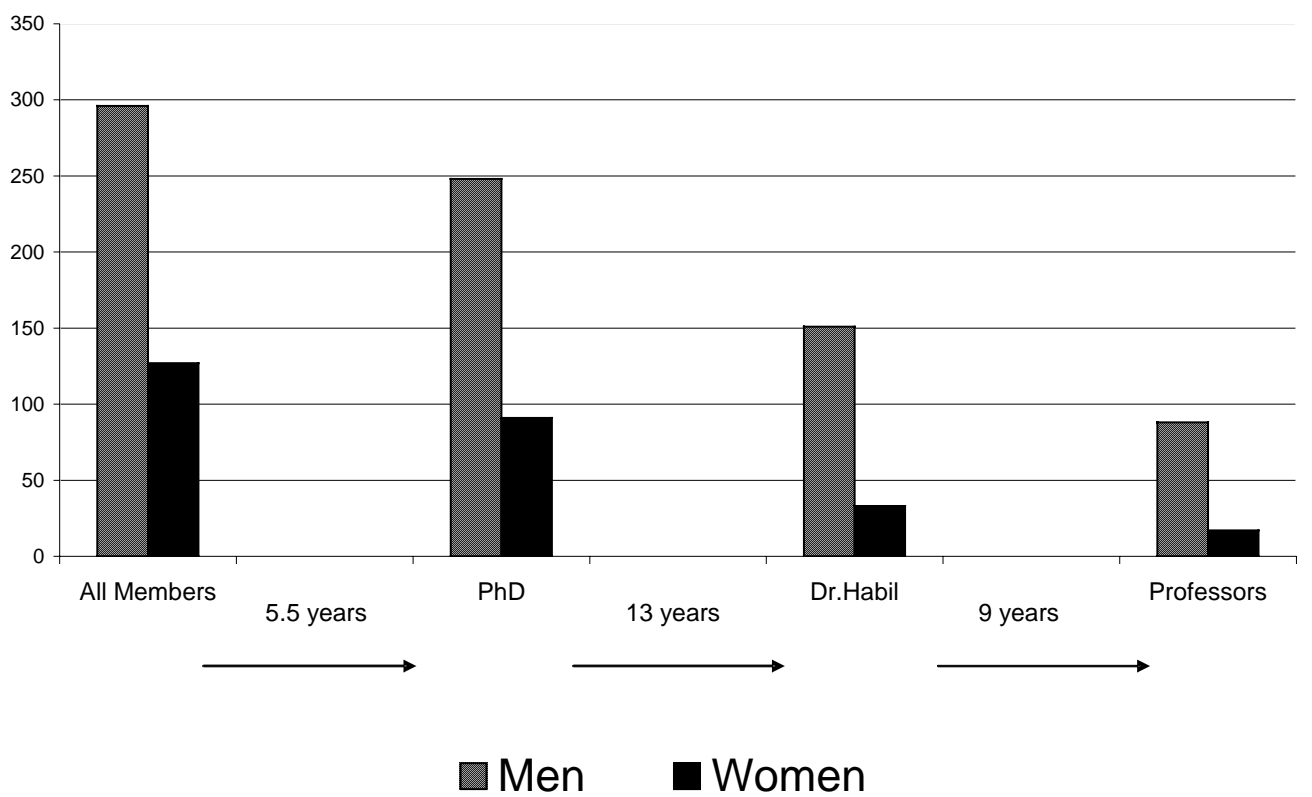

Fig. (2).

There seems to be a larger role for personal circumstances, about which we have no information.

The pre1975 cohort of students going for a Ph.D. was quicker in concluding this step than the two cohorts between 1976 and 1995. The post1995 cohort was even faster; see also the average durations for each cohort given in Table $\mathbf{1}$ above. The pattern shows that the length of the Ph.D. step increased in the 1970s and 1980s, and is declining again ever since.

Being abroad has no significant effect. Having obtained a stipend gains the candidate only about half a year on average, but the effect is not significant. Changing universities slows the candidate down by about a year, most likely because the change required effort to find a new position; a time during which one cannot work on his/her own Ph.D. thesis. Changing the sources of financing per se, i.e. without changing the location, has no such effect.

Types of financing show three significant effects: Financing the step with a position at a university, which is given the definition of the categorization - coupled with a teaching assignment, slows the candidate down by about one year. Being financed by the parents seems to exert some pressure on the candidate, as those who were financed this way concluded the step quicker - by about one and a half years. On the other hand, being funded by social assistance or unemployment assistance slows people down. Either because the Ph.D. candidate is temporarily not pursuing the project in earnest, is questioning the decision to embark into an academic career, or, more likely, because the candidate is busy searching for employment and financing. The time between grant application and the funding authority's decision may be spent formally unemployed. In the end, it is important to remember that those who answered positively to this question nevertheless accomplished the Ph.D.
A frequent mode of financing is working in a research project which, in turn, is financed by a research grant. This does not slow candidates down, implying that usually they are not occupied with activities which are completely or relatively useless for their own work. Rather the topic of the Ph.D. thesis and the research project are somewhat related.

Since the Ph.D. step is not a final decision about the theme or the sub-discipline in which the person will be active later on, we have not included the theme of the respondent's studies in our consideration. Moreover, since many respondents are now beyond the Ph.D. step, they may refer to their current area of work when answering this particular question.

As for age, a pattern shared by all steps is that younger candidates take more time to accomplish a step. Older candidates, probably because they feel the pressure more intensely, speed up their studies significantly.

\section{The Habilitation Step}

Going through the habilitation step takes substantially longer than getting a Ph.D. There is also more variation in the duration of the step compared to the Ph.D. step; cf. also Table 1b above. An initial finding which may indicate a personal characteristic as a factor is that candidates who took longer to get the Ph.D. need even more time to complete habilitation. Excluded are those who got professorship without having to achieve habilitation.

There are no significant effects of gender. If women decide to have a child, they do so in the Ph.D. step. While we cannot conclude anything about whether women make the step less frequently than men, we can say that given that a woman has decided to go for habilitation, there are no more significant differences compared to men, in the time required to complete the step. 
The way this step is financed has several strong effects, none of which are, however, significant. Working at an university, i.e. having a teaching assignment, is the "standard" case, but has, just as other "typical" sources of financing, no significant prolonging effect. Receiving a stipend or being funded by a research grant does not speed up things. Again, those types of financing aimed explicitly at allowing the recipient to concentrate on his/her own research do not achieve this. Those who were working outside academia (in the public sector or the private industry), or were financed by their partner or spouse, take significantly longer. The former effect is likely due to people who left academia but returned later on. Again, one has to keep in mind that those who participated in the survey did, in the end, return, regardless of what they did in the meantime. The latter effect is most likely equivalent with being temporarily without employment; in this situation, time and effort are predominantly spent looking for an employment.

Given that by choosing a theme for habilitation a candidate makes a more than preliminary decision on the later area of specialization, we looked at the effects of topics from this step on. Of the topics for which we have data, political sociology, covering issues like electoral studies, is

Table 2. Factors for the Duration of Career Steps for Political Scientists

\begin{tabular}{|c|c|c|c|c|c|}
\hline dpromo & b & $\mathbf{t}$ & dhabil & b & $\mathbf{t}$ \\
\hline & & & dpromo & 1,202 & 5,31 \\
\hline University Position & 1,113 & 2,13 & University Position & 1,746 & 0,84 \\
\hline Research Project & 0,433 & 0,69 & Research Project & 1,940 & 0,83 \\
\hline Stipend & 0,781 & 0,97 & Stipend & 4,207 & 1,94 \\
\hline Parents & $-1,497$ & $-2,36$ & Parents & $-0,803$ & $-0,22$ \\
\hline Personal Savings & 0,347 & 0,43 & Personal Savings & 0,058 & 0,02 \\
\hline Unemployment/Social Aid & 2,126 & 2,49 & Unemployment/Social Aid & 3,347 & 0,97 \\
\hline & & & GermanPoliticalSystem & 0,080 & 0,1 \\
\hline & & & Political Sociology & $-1,506$ & $-1,71$ \\
\hline & & & Policy Studies & $-0,006$ & $-0,01$ \\
\hline & & & Administrative Sciences & 0,332 & 0,25 \\
\hline & & & Comparative Politics & $-0,531$ & $-0,69$ \\
\hline & & & International Relations & $-0,728$ & $-0,77$ \\
\hline & & & Political Education & 2,450 & 1,74 \\
\hline cohort7685 & 1,031 & 2,13 & cohort7685 & 0,608 & 0,71 \\
\hline Abroad & 0,332 & 0,9 & Abroad & 0,196 & 0,26 \\
\hline MultiFin & $-0,177$ & $-0,27$ & MultiFin & $-1,107$ & $-0,49$ \\
\hline Mobility & 1,059 & 2,98 & Mobility & 0,101 & 0,14 \\
\hline constant & 7,245 & 3,48 & constant & 14,814 & 2,99 \\
\hline $\mathrm{N}$ & 326 & & & 147 & \\
\hline $\mathrm{R} 2$ & 0,21 & & & 0,45 & \\
\hline Adj. R2 & 0,16 & & & 0,33 & \\
\hline
\end{tabular}


(Table 2) Contd.....

\begin{tabular}{|c|c|c|c|c|c|c|c|c|}
\hline Waiting & b & $\mathbf{t}$ & Waiting & $\mathbf{b}$ & $\mathbf{t}$ & Waiting & $\mathbf{b}$ & $\mathbf{t}$ \\
\hline dpromo & $-0,123$ & $-0,53$ & dpromo & 0,247 & 0,98 & dpromo & 0,164 & 0,7 \\
\hline dhabil & 0,078 & 1,12 & dhabil & $-0,030$ & $-0,38$ & dhabil & $-0,025$ & $-0,34$ \\
\hline \multicolumn{9}{|l|}{ Mode of Financing } \\
\hline University Position & 2,177 & 1,64 & & 1,727 & 1,20 & & 1,188 & 0,82 \\
\hline Research Project & $-1,315$ & $-0,66$ & & $-1,647$ & $-0,77$ & & $-1,468$ & $-0,69$ \\
\hline Private-/Public Services & 3,723 & 2,14 & & 3,018 & 1,59 & & 3,024 & 1,62 \\
\hline Stipend & $-0,962$ & $-0,39$ & & $-2,445$ & $-0,90$ & & $-3,284$ & $-1,17$ \\
\hline Stand-in-Professorship & 2,096 & 1,17 & & 3,693 & 1,88 & & 3,342 & 1,78 \\
\hline Partner's Income & 3,511 & 1,19 & & 5,518 & 1,68 & & 7,037 & 2,06 \\
\hline Personal Savings & $-2,542$ & $-0,85$ & & $-0,138$ & $-0,04$ & & 0,051 & 0,02 \\
\hline Unemployment/Social Aid & 5,321 & 2,26 & & 3,857 & 1,46 & & 3,338 & 1,31 \\
\hline \multicolumn{9}{|l|}{ Subdiscipline } \\
\hline Political Theory & 1,446 & 1,13 & & 0,760 & 0,56 & & 0,616 & 0,45 \\
\hline Methods & $-2,056$ & $-1,07$ & & $-2,595$ & $-1,28$ & & $-2,441$ & $-1,23$ \\
\hline GermanPoliticalSystem & 0,066 & 0,05 & & $-1,974$ & $-1,54$ & & $-2,332$ & $-1,87$ \\
\hline Political Sociology & $-0,010$ & $-0,01$ & & $-1,274$ & $-0,95$ & & $-1,720$ & $-1,3$ \\
\hline Policy Studies & $-1,392$ & $-1,1$ & & $-1,109$ & $-0,81$ & & $-1,197$ & $-0,89$ \\
\hline Administrative Sciences & $-0,881$ & $-0,49$ & & $-1,677$ & $-0,87$ & & $-1,813$ & $-0,95$ \\
\hline Comparative Politics & 1,131 & 0,92 & & 1,104 & 0,86 & & 0,991 & 0,77 \\
\hline International Relations & 0,235 & 0,19 & & $-1,321$ & $-1,00$ & & $-1,164$ & $-0,9$ \\
\hline Political Education & 3,104 & 1,87 & & 2,924 & 1,65 & & 2,434 & 1,38 \\
\hline multi_task & $-0,307$ & $-0,17$ & & 1,070 & 0,56 & & 1,761 & 0,97 \\
\hline Aktivity & $-0,039$ & $-0,09$ & & 0,081 & 0,18 & & $-0,036$ & $-0,08$ \\
\hline prof8089 & 3,163 & 1,99 & entry 8089 & $-0,671$ & $-0,50$ & cohort7685 & 0,043 & 0,04 \\
\hline prof9099 & 6,417 & 4,41 & entry9099 & $-3,018$ & $-2,08$ & cohort8695 & $-3,366$ & $-2,24$ \\
\hline prof 2000 & 5,430 & 3,28 & entry 2000 & $-8,396$ & $-1,87$ & cohort1996 & $-14,901$ & $-2,24$ \\
\hline age_phd & $-0,378$ & $-2,17$ & age_phd & $-0,327$ & $-1,59$ & age_phd & $-0,327$ & $-1,75$ \\
\hline Women & $-1,433$ & $-1,21$ & Women & 0,089 & 0,07 & Women & $-0,190$ & $-0,15$ \\
\hline Stipend & 1,210 & 1,16 & Stipend & 2,291 & 2,12 & Stipend & 2,272 & 2,11 \\
\hline Abroad & 0,348 & 0,32 & Abroad & $-0,499$ & $-0,43$ & Abroad & $-0,600$ & $-0,52$ \\
\hline MultiFin & $-1,456$ & $-0,72$ & MultiFin & $-1,003$ & $-0,44$ & MultiFin & $-0,392$ & $-0,18$ \\
\hline Mobility & 1,272 & 1,3 & Mobility & 1,190 & 1,16 & Mobility & 1,348 & 1,35 \\
\hline constant & 12,963 & 2,36 & constant & 17,559 & 2,89 & _cons & 17,182 & 2,99 \\
\hline $\mathrm{N}$ & 113 & & & 113 & & & 113 & \\
\hline $\mathrm{R} 2$ & 0,53 & & & 0,46 & & & 0,475 & \\
\hline Adj. R2 & 0,36 & & & 0,27 & & & 0,283 & \\
\hline
\end{tabular}

the only one in which the habilitation is achieved usually somewhat, albeit not significantly, faster. On the other hand, focusing on political education prolongs the step by about two years. The effect is not significant because there are relatively few candidates choosing this subject area.
Being abroad for some time, or changing universities during the step, again has no effect on the duration of the step; most likely because university changes are happening so often in this step. The same is true for multiple sources of financing. Given the length of the step, it is likely that the candidate will have to find more than one source of 
financing, making multiple sources of financing a common feature of all candidates.

Age at the beginning of the phase, i.e. the age at which the Ph.D. was obtained, is almost significant, with older candidates being quicker and catching up. The cohort of 1986 to 1995 was significantly faster in achieving habilitation, however, the reasons for this remain unclear. Apart from this, there are no differences in the time required for the step among cohorts.

The explanatory power of the model increases substantially, with both $\mathrm{R}^{2}$ and adjusted $\mathrm{R}^{2}$ doubling. While the variation in the way the step is executed is larger, the factors for which we have information can explain the differences better than in the Ph.D. step.

\section{Waiting Time for Professorship}

The length required to achieve the formal qualification for professorship does not matter for the time required to get the "first call". After habilitation, the durations of the two previous steps no longer matter. On average, a candidate waits 9 years to get the first call, cf. section a) in Table $\mathbf{1}$. Usually, this time is spent working at a university. The variation in the waiting period is somewhat lower than for the habilitation step. The explanatory power of the model increases again, $\mathrm{R}^{2}$ increases to .53 and the adjusted $\mathrm{R}^{2}$ to .36 .

Looking at the modes of how to finance the time spent waiting and searching for the "first call" yields only two significant effects, both increasing the length of the period. The first is again a temporary exit from academia to work in the public sector or the private industry. The second is being unemployed. Together with the weakly significant effect of being financed by a partner or spouse, this can be interpreted as a temporary leaving of academia. Interestingly, working as a stand-in professor does not reduce the waiting time. As for themes, Political Education is the area in which candidates have to wait longest for the first call. For all other themes, the waiting period does not differ in any significant way from the average.

Of the personal features, the age when finishing the Ph.D. step reduces waiting time significantly, but only by about 4 months. There are no differences between women and men. Furthermore, none of the typical features which are seen as conducive to getting a professorship are significant: being active in the DVPW, as a proxy of networking, mobility, having been abroad, or having obtained a stipend at least once during the career, all have no effect.

The strongest effect can be found for the variables capturing time related features: the cohort, the time of market entry, and the professorship cohort, given in the second part of Table 2. The three variants we look at basically capture the same thing, namely the supply of professorships, i.e. features beyond the control of the candidate. For instance, those who obtained professorship in the 1990s did so after waiting a long time, while those entering the academic job market at this time had a shorter waiting time. In this regard, it is important to keep in mind that due to the length of the waiting period the entry 9099 group is not identical to the prof2000 group. The waiting time is nowadays much longer than it was for those who received their first call before 1979. After a peak in the 1990 s, the expected waiting period is again dropping for those who received their first call only recently. There is a cyclical pattern in the frequency of vacant positions: a finding which is supported by the data in Table 1c above. Overall, obtaining of a professorship seems to be beyond the control of the candidate.

\section{SUMMARY AND CONCLUSION}

Supplementary to studies which focus on the decisions in an academic career, we analyzed how the way certain steps are conducted affects the duration of the step. While we cannot explain why a decision is made, we can explain the success (in terms of accomplishing a step fast or slow), given that a certain decision was made.

An initial finding we would like to emphasize is that despite a strict regulatory framework, patterns in the length of a career step are far from homogeneous. The habilitation step has the most variation, but this variation can be explained quite well using period effects. On the other hand, the $\mathrm{Ph} . \mathrm{D}$. step is the phase where most variation remains unexplained. Many features apart from those for which we have information influence how this step is made. Later steps in the career are more uniform: the explanatory power of the factors for which we have data increases dramatically in these later steps.

It is also interesting to see which of the features and events have no effect, at least not on the length of a step. For instance, a stipend, often seen as a mark of excellence, does not have an effect on duration. While it is aimed explicitly at allowing the recipient to work unhindered by other distractions, and hence faster, there is no indication that this effect is achieved. Mobility, changing the university during a step, is somewhat of a hindrance.

Looking at the lengths, we find effects for women only in the first step, when achieving the Ph.D. Given the age at this step, we would guess that it is due to pregnancy. Later on, there are no more differences. The differences in number of female and male professors may be the result of the initial composition of the cohort of students. It may be because women leave more often. Following the youngest cohort in the sample, which is composed of an equal number of women and men, may give answers about the drop out rates. If the gender distribution now is more equal, and the dropout rates are also equal, one would expect that, in the long run, the gender distribution among the higher echelons will also become more equal.

Looking at the last step of getting a professorship, we would argue that the supply side of the academic market, is more important than the features of the candidates: there are cycles, periods in which many professors retire and many existing positions become available, followed by periods during which all positions have been recently occupied and the holders of the positions will remain in these positions for several years. Such retirement waves occurred in the 1970s, the 1990s and recently as of 2005 . There was also a period in which positions were created, e.g. the late 1960s/early 1970s. Being on the market at this point in time increased the chances of getting professorship quicker. 
Given the effect of age at the beginning of a certain step, one could get the impression of a kind of "target age" by which a certain step should be accomplished: those who are younger take more time while those who are older take less time.

\section{REFERENCES}

[1] Hillmert S. Altersstruktur und Karrierewege der Professorinnen und Professoren in der deutschen Soziologie. KZfSS 2003; 55(1): 116-35.

[2] Plümper T, Schimmelfennig F. Wer wird Prof - und wann? Berufungsdeterminanten in der deutschen Politikwissenschaft. PVS 2007; 48(1): 97-117.

[3] Corak M, Lips G, Zhao J. Family income and participation in postsecondary education. Bonn: IZA Discussion Paper 9772004.

[4] Abedi J, Benkin E. The effects of students' academic, financial, and demographic variables on time to the doctorate. Res High Educ 1987; 27(1): 3-14

[5] Gillingham L, Senecal JJ, Taussig MK. The determinants of progress to the doctoral degree. Res High Educ 1991; 32(4): 44968.

[6] Kahn S. Gender differences in academic career paths of economists. Am Econ Rev 1993; 83(2): 52-6.

[7] Ginther DK, Kahn S. Women in economics: moving up or falling off the academic career ladder? J Econ Perspect 2004; 18(3): 193214.

[8] Preston AE. Why have all the women gone? A study of exit from the science and engineering professions. Am Econ Rev 1994; 84(5): 1446-62.

[9] Frank Fox M. Women in scientific fields: doctoral education and academic careers. Workshop on Women's Advancement American Political Science Association 2004.
[10] Long JS, Allison PD, McGinnis R. Entrance into the academic career. Am Sociol Rev 1979; 44(5): 816-30.

[11] Long JS, Frank Fox M. Scientific careers: universalism and particularism. Annu Rev Sociol 1995; 21: 45-71.

[12] Ginther DK, Kahn S. Does science promote women? Evidence from academia 1973-2001. Cambridge, Mass.: NBER Working Paper No 12691, 2006

[13] Robin SR. The effect of supervision on Ph.D. duration, publications and job outcomes. Louvain: IRES (Institute for Social and Economic Research) Catholic University of Louvain 2002.

[14] Chevalier A, Conlon G. Does it pay to attend a prestigious university? Bonn: IZA Discussion Paper 848, 2003.

[15] Granovetter M. Getting a job: a study of contacts and careers Chicago: University of Chicago Press 1974.

[16] Roebken H. Departmental networks: an empirical analysis of career patterns among junior faculty in Germany. Higher Educ 2007; 54(1): 99-113.

[17] Laudel G. The quality myth: promoting and hindering conditions for acquiring research funds. Higher Educ 2006; 52(3): 375-403.

[18] Easterlin RA. Birth and Fortune: the impact of numbers on personal welfare. New York: Basic Books, 1980.

[19] Musselin C. European academic labor markets in transition. Higher Educ 2005; 49(1-2): 135-154

[20] Long JS, Allison PD, McGinnis R. Rank advancement in academic careers: sex differences and the effects of productivity. Am Soc Rev 1993; 58(5): 703-22.

[21] Caplow T, McGee RI. The academic marketplace. New York: Basic Books, 1958.

[22] King G, Keohane RO, Verba S. Designing social inquiry. Princeton: Princeton University Press 1994.

[23] Preston AE. Leaving science: occupational exit from scientific careers. New York: Russell Sage Foundation 2004.

(C) Knodt and Kotzian; Licensee Bentham Open.

This is an open access article licensed under the terms of the Creative Commons Attribution Non-Commercial License (http: //creativecommons.org/licenses/bync/3.0/), which permits unrestricted, non-commercial use, distribution and reproduction in any medium, provided the work is properly cited. 